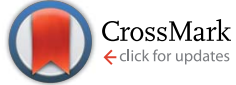

Cite this: Analyst, 2014, 139, 5547
Received 28th May 2014

Accepted 14th August 2014

DOI: $10.1039 / c 4 a n 00966 \mathrm{e}$

www.rsc.org/analyst

\section{Oncologic photodynamic diagnosis and therapy: confocal Raman/fluorescence imaging of metal phthalocyanines in human breast cancer tissue in vitro}

\author{
Halina Abramczyk, ${ }^{* a}$ Beata Brozek-Pluska, ${ }^{a}$ Jakub Surmacki, ${ }^{a}$ Jacek Musial ${ }^{b}$ \\ and Radzislaw Kordek ${ }^{\mathrm{b}}$
}

Raman microspectroscopy and confocal Raman imaging combined with confocal fluorescence were used to study the distribution and aggregation of aluminum tetrasulfonated phthalocyanine $\left(\mathrm{AlPcS}_{4}\right)$ in noncancerous and cancerous breast tissues. The results demonstrate the ability of Raman spectroscopy to distinguish between noncancerous and cancerous human breast tissue and to identify differences in the distribution and aggregation of aluminum phthalocyanine, which is a potential photosensitizer in photodynamic therapy (PDT), photodynamic diagnosis (PDD) and photoimmunotherapy (PIT) of cancer. We have observed that the distribution of aluminum tetrasulfonated phthalocyanine confined in cancerous tissue is markedly different from that in noncancerous tissue. We have concluded that Raman imaging can be treated as a new and powerful technique useful in cancer photodynamic therapy, increasing our understanding of the mechanisms and efficiency of photosensitizers by better monitoring localization in cancer cells as well as the clinical assessment of the therapeutic effects of PDT and PIT.

\section{Introduction}

Optical imaging systems are ideally suited for the early detection of epithelial diseases, including most cancers, and for the assessment of tumor margins and therapy response. Raman imaging is an emerging field that has generated significant interest both for label-free Raman methods as well as for surface enhanced Raman methods with nanoparticles, Raman reporters and bioconjugates. The medical applications of Raman imaging are a rapidly developing area of molecular biospectroscopy that create new possibilities in human cancer diagnostics. ${ }^{1-10}$ Alternatively, photodynamic methods (PDT, PDD, PIT) in cancer are powerful and promising treatment modalities related to the use of photosensitizers as agents to destroy cancer cells. Current clinical strategies and future views in photodynamic methods have been discussed recently. ${ }^{11-17} \mathrm{We}$ will demonstrate that combining Raman and fluorescence imaging is a powerful method that is useful in photodynamic therapy (PDT) of cancer.

In PDT, the photosensitizers are administered to a patient intravenously and activated using laser light of a specific

${ }^{a}$ Lodz University of Technology, Institute of Applied Radiation Chemistry, Laboratory of Laser Molecular Spectroscopy, Wroblewskiego 15, 93-590 Lodz, Poland. E-mail: abramczy@mitr.p.lodz.pl; Fax: +48 42 684-00-43; Tel: +48 42 6313175; +48 42 6313188

${ }^{b}$ Medical University of Lodz, Department of Pathology, Chair of Oncology, Paderewskiego 4, 93-509 Lodz, Poland wavelength. The irradiation results in a sequence of photochemical and photobiological reactions that cause irreversible photodamage to tumor tissues. The detailed mechanism of photodynamic reactions in the tissues is not completely understood yet; however, three mechanisms are taken into account, and the predominance of one of these mechanisms depends on the concentration of oxygen in tissues, Type I, II and III. In Type II PDT, the excited triplet state of the photosensitizer $\left({ }^{3} \mathrm{PS}^{*}\right)$ is reached through the intersystem crossing (ISC) from the first excited singlet state $\left({ }^{1} \mathrm{PS}^{*}\right)$, derived from the ground state ( $\left({ }^{1} \mathrm{PS}\right)$, by the absorption of laser light. Due to the sufficiently long lifetime of the triplet state $\left({ }^{3} \mathrm{PS}^{*}\right)$, a photosensitizer can interact efficiently with the environment of the tissue. The ${ }^{3} \mathrm{PS} *$ state of the photosensitizer reacts directly with the triplet state oxygen molecule $\left({ }^{3} \mathrm{O}_{2}\right)$, generating highly toxic singlet oxygen $\left({ }^{1} \mathrm{O}_{2}^{*}\right)$ and effectively destroying tumor tissue. This process competes with the radiation (fluorescence, phosphorescence) and radiationless (internal conversion) deactivation of the ${ }^{3} \mathrm{PS} *$ state of the photosensitizer. ${ }^{18,19}$

The other mechanism (Type I) occurs when the oxygen concentration in the environment of the tissue is limited. In this case, photooxidation reactions dominate with the formation of radicals in a tumor tissue. As a result of hydrogen or electron transfer between the excited photosensitizer and the tissue, ion radicals are formed, which destroy cancer cells. Alternatively, the photosensitizer may also react directly with the target (Type III). 
As important as the mechanisms of photoreactions upon light irradiation is the localization of the photosensitizer. Conceptually, photosensitizers accumulate in both types of tissues, normal and cancerous, but the faster clearance from the normal tissue allows for a relatively selective accumulation and selective PDT. The resulting differences in accumulation allow for the selective destruction of cancer cells and reduce the damage to normal tissue. The ratio of the photosensitizer concentration in the tumor to normal tissue depends on the type of photosensitizer and the type of tumor tissue. ${ }^{19}$

The initial subcellular localization of each photosensitizer depends on hydrophobic and hydrophilic properties, protein binding affinity and charge. The hydrophobic and hydrophilic properties of the photosensitizers are related to their water solubility, which regulates aggregation and the efficiency of singlet oxygen production. Taking into account the solubility of photosensitizers, one can distinguish hydrophobic photosensitizers that tend to accumulate in lipid-containing cellular structures (e.g., cell membrane and endoplasmic reticulum) and hydrophilic photosensitizers that accumulate in water-rich regions (e.g., lysosomes in the cell). Amphiphilic photosensitizers accumulate in both water- and lipid-rich regions.

The charge determines the anionic, cationic, amphiphilic or neutral characteristics of photosensitizers and plays an important role in the cellular uptake and photodynamic efficacy of photodynamic therapy (PDT). ${ }^{\mathbf{2 0 , 2 1}}$ Studies have also demonstrated that a water-soluble tetrasubstituted cationic aluminum phthalocyanine $(\operatorname{AlPcN}(4))$ efficiently bound to phospholipid membranes behaved similar to anionic tetrasulfonated aluminum and zinc phthalocyanine complexes. ${ }^{22}$ Thus, the binding of tetrasulfonated metallophthalocyanines to phospholipid membranes has been suggested to be primarily determined through metal-phosphate coordination. ${ }^{22}$ Among the hydrophilic photosensitizers, anionic derivatives of metal complexes of phthalocyanines with sulpho substituents, such as zinc tetrasulfonated phthalocyanine $\left(\mathrm{ZnPcS}_{4}\right)$ or $\mathrm{AlPcS}_{4}$, are some of the best targets for the generation of novel photosensitizers. Metal phthalocyanines have become popular in PDT since Ben-Hur ${ }^{23}$ reported the anticancer properties of phthalocyanine aluminum chloride. The efficacy of phthalocyanine derivatives as photosensitizers in recent years was significantly enhanced by employing short-pulse irradiation with a femtosecond laser, which increases selectivity by reducing the photothermal effect on normal cells, and targeted photodynamic therapy, which increases specificity by employing photosensitizer-nanoparticle conjugates. ${ }^{24-30}$ The targeted PDT is based on molecular recognition towards specific cell surface receptors, which can be achieved by conjugation with a specific antibody. Recently, targeted PDT has been employed in breast cancer cells using Her2 antibody-phthalocyanine-gold nanoparticle conjugates. ${ }^{31}$

In this study, we develop a PDT method based on confocal Raman imaging and fluorescence imaging to simultaneously monitor the morphology and biochemistry of the target cells as well as the localization of the photosensitizer in the cells activated by light for targeted PDT. Furthermore, because the photosensitizer emits a diagnostic fluorescence, the combined confocal Raman/fluorescence imaging can be used to monitor the effect of light exposure on the morphology and biochemistry of the target tissue and the localization of the photosensitizer as well as to non-invasively monitor therapeutic effects in the future. Tetrasulfonated aluminum phthalocyanine was selected as a hydrophilic and anionic photosensitizer.

The main goal of this study is to present the ability of Raman spectroscopy and imaging to distinguish between noncancerous (normal) and cancerous human breast tissue and to identify differences in the distribution of aluminum tetrasulfonated phthalocyanine, the photosensitizer in PDT therapy, in both types of cells.

\section{Results and discussion}

In this section, the results of the confocal microRaman/fluorescence images and spectra on the noncancerous and the cancerous human breast tissues of the same patient (P104, infiltrating ductal cancer, GX) without addition of photosensitizers are presented. In the next step, we add photosensitizers at concentrations corresponding to standard PDT practical applications. Before we present the results, we will describe the types of cancer analyzed in this study.

Ductal cancer develops in the epithelial cells of the ducts. During disease progression, the normal polar organization of the luminal epithelial cells is lost. As these cells differentiate and proliferate, the epithelial cells completely fill the lumen of the duct. In infiltrating ductal cancer, the transformed epithelial cells cross the basement membrane, and migrate through the basement membrane into the surrounding structures, which are predominantly but not exclusively composed of adipose tissue, fibroblasts, connective tissue, and collagen fibers. These structures can be easily observed in Fig. 1A and 2A, where we present histological images. The histological images demonstrate the morphology, as hematoxylin and eosin (H\&E) staining allows the visualization of various structures in tissues. Hematoxylin stains all basophilic components blue, especially the nucleus, containing DNA and RNA, and the rough endoplasmic reticulum, with an accumulation of ribosomes, as a result of coordination bond formation between aluminum and the phosphorous atoms of the DNA and RNA. Eosin stains the cytoplasm, connective tissue and collagen fibers (eosinophilic substances) red due to ionic bonds between the anionic dye and cationic plasma proteins..$^{32,33}$

The histological images demonstrate the morphology of the tissue but cannot provide any information about the biochemistry of the observed structures. However, biochemical information can be provided by Raman imaging. A detailed understanding of the biochemistry of the tissue will not only improve our current knowledge about the structure itself but will also lead to significant advances in our understanding of processes occurring during the development of cancer. Here, we will demonstrate that the 'Raman biopsy' creates new possibilities in human cancer diagnostics because it can identify the biochemical compounds accumulated in the biological structures. 
a)

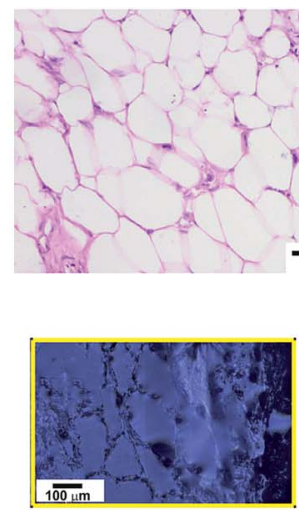

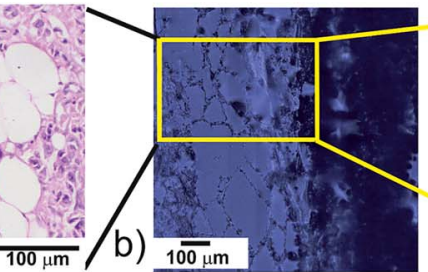

b)

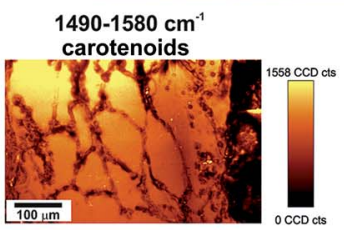

2888

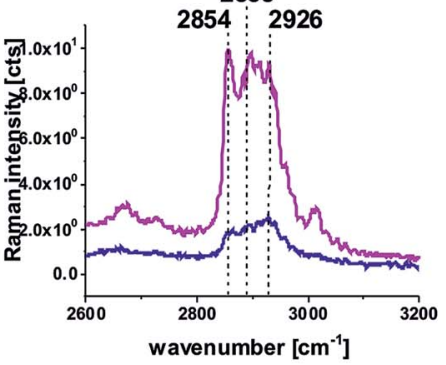

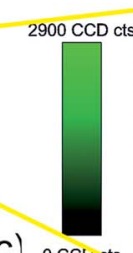

C) 0 cCL its $\overline{100 \mu \mathrm{m}}$
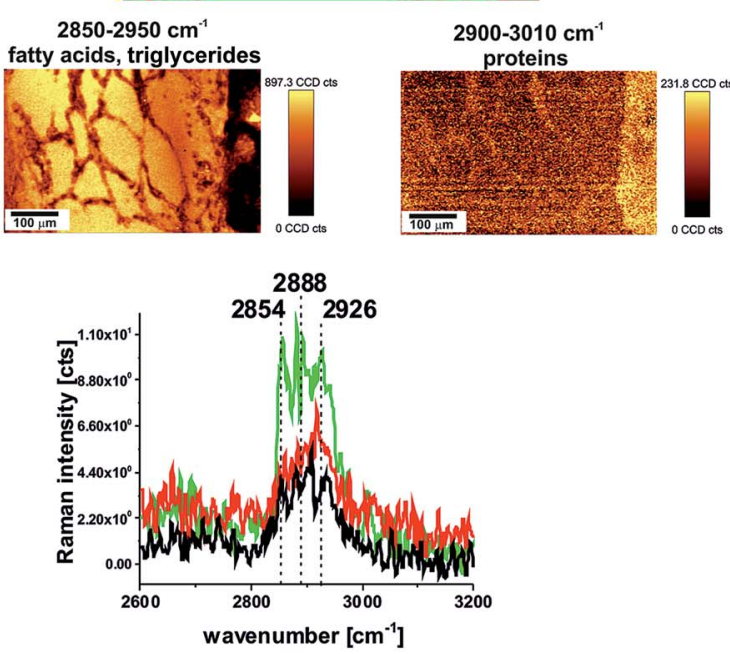

f)

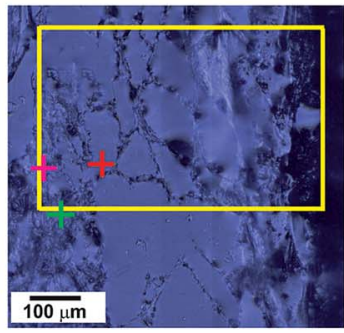

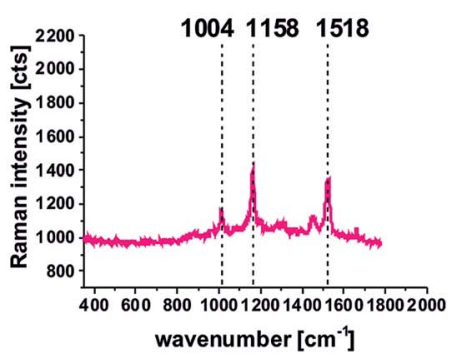
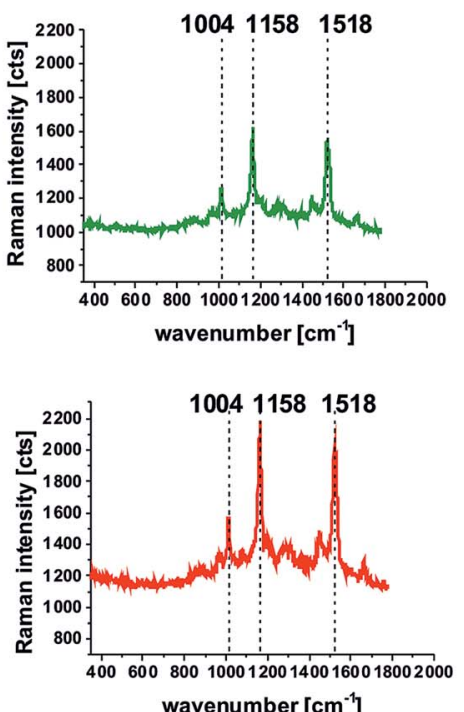
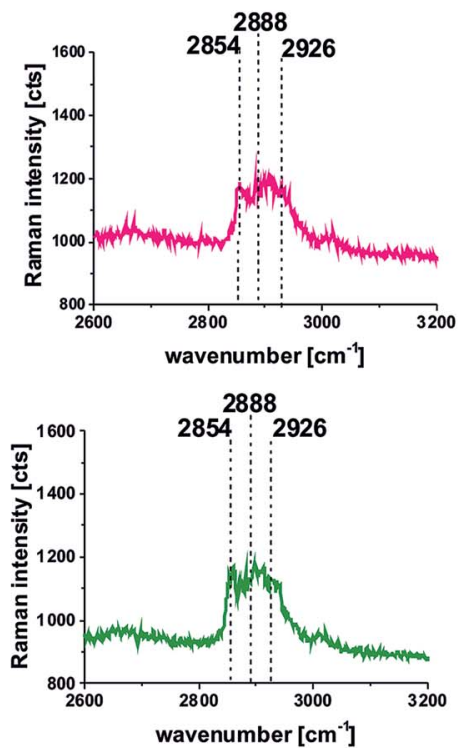

2888

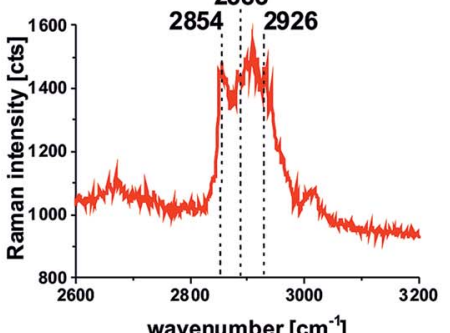

Fig. 1 Patient P104, the breast tissue from the margin of the tumor mass: H\&E-stained histological image (a), microscopy image (1000 $\times 1000 \mu \mathrm{m}, 2000$ $\times 2000$ pixels, spatial resolution $0.5 \times 0.5 \mu \mathrm{m})$ composed of 121 single video images (b), Raman image $(550 \times 350 \mu \mathrm{m}, 250 \times 150$ points per line/lines per image, resolution $2.2 \times 2.3 \mu \mathrm{m})$ (c), microscopy image $(550 \times 350 \mu \mathrm{m}, 250 \times 150$ points per line/lines per image, resolution $2.2 \times 2.3 \mu \mathrm{m})$, images for the filters for spectral regions: $1490-1580 \mathrm{~cm}^{-1}, 2850-2950 \mathrm{~cm}^{-1}$, and $2900-3010 \mathrm{~cm}^{-1}(\mathrm{~d})$, average spectra used for the basis analysis method and single spectra corresponding to different areas of the Raman image (colors of the spectra corresponding to colors of the Raman image are presented in part (c)) (e), and microscopy image $(550 \times 350 \mu \mathrm{m}, 250 \times 150$ points per line/lines per image, resolution $2.2 \times 2.3 \mu \mathrm{m})$ and single spectra of various sites of the sample, colors of the spectra correspond to the colors of the crosses in the microscopy image; integration times $10 \mathrm{~s}, 2$ accumulations (f). 
a)

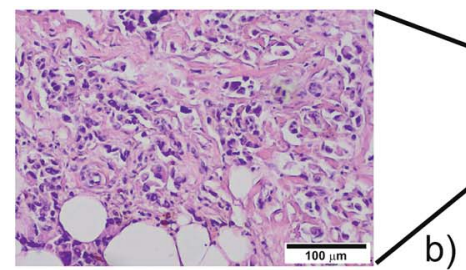

d)

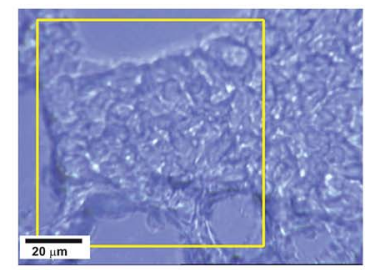

e)

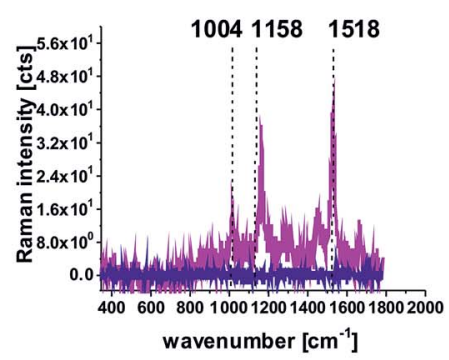

b)

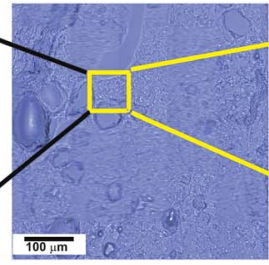

c)
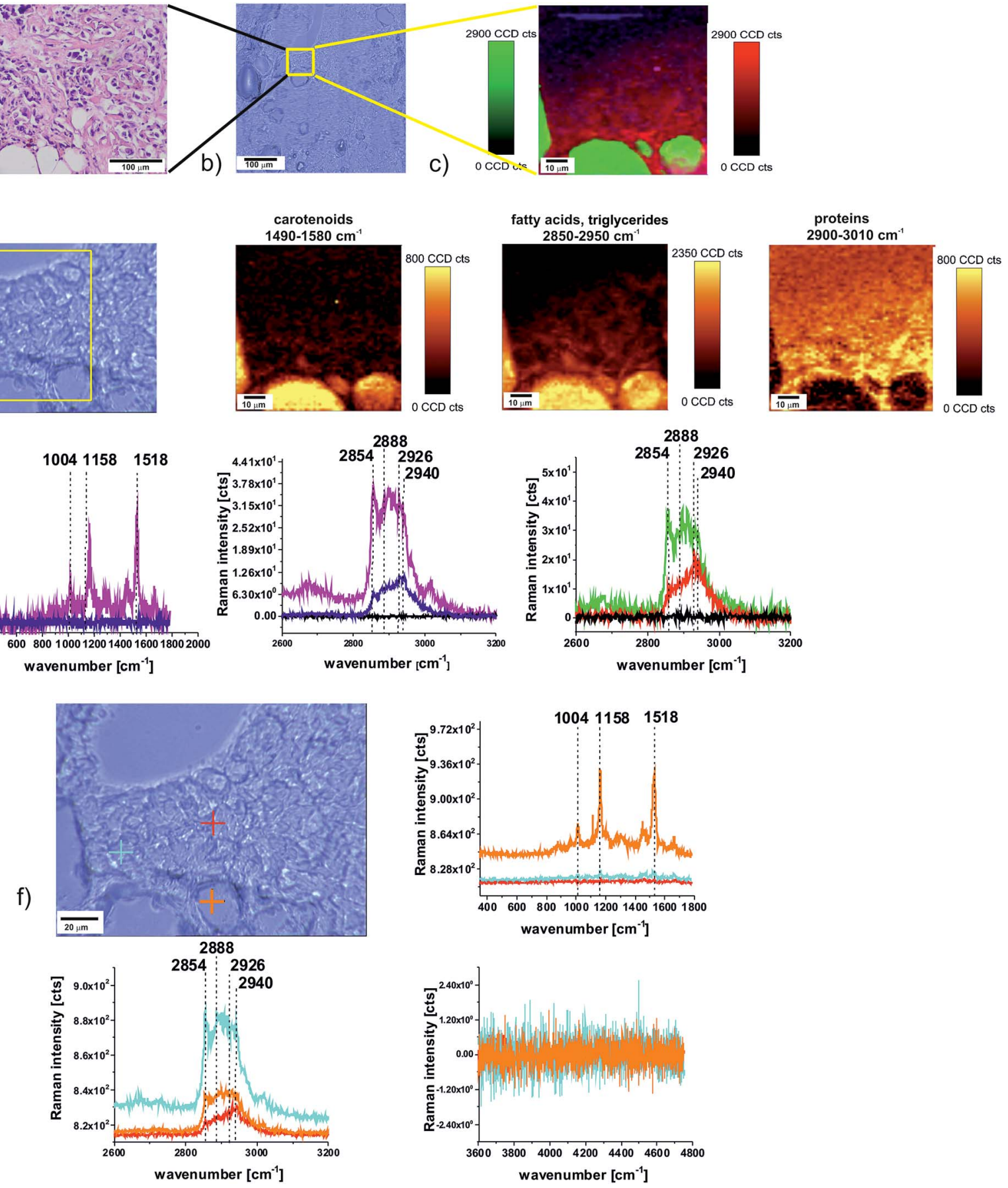

Fig. 2 Patient P104, the breast tissue from the tumor mass: H\&E-stained histological image (a), microscopy image $(2000 \times 2000 \mu \mathrm{m}, 300 \times 300$ pixels, spatial resolution $0.66 \times 0.66 \mu \mathrm{m})$ composed of 400 single video images (b), Raman image $(80 \times 80 \mu \mathrm{m}, 60 \times 60$ points per line/lines per image, resolution $1.3 \times 1.3 \mu \mathrm{m})$ (c), microscopy image $(2000 \times 2000 \mu \mathrm{m}, 300 \times 300$ pixels, spatial resolution $0.66 \times 0.66 \mu \mathrm{m})$, images for the filters for spectral regions: $1490-1580 \mathrm{~cm}^{-1}, 2850-2950 \mathrm{~cm}^{-1}$, and $2900-3010 \mathrm{~cm}^{-1}$ (d), average spectra used for the basis analysis method and single spectra corresponding to different areas of the Raman image (colors of the spectra corresponding to colors of the Raman image presented in part (c)) (e), microscopy image $(2000 \times 2000 \mu \mathrm{m}, 300 \times 300$ pixels, spatial resolution $0.66 \times 0.66 \mu \mathrm{m})$ and single spectra of various sites of the sample, colors of the spectra correspond to the colors of the crosses in the microscopy image; integration times $10 \mathrm{~s}, 2$ accumulations (f).

The histological and Raman images and the typical average Raman spectra of the breast tissue from the margin of the tumor mass and the cancerous breast tissue from the tumor mass are presented in Fig. 1 and 2.
One can see from Fig. 1 and 2 that the Raman images (c) reveal the inhomogeneous distribution of the different compounds in the samples and resemble almost perfectly the microscopy images (b) and the conventional histological images (a) obtained from the tissue sections stained with hematoxylin 
and eosin (H\&E). The Raman image is not prone to subjective interpretations and monitors biological tissues without any external agents, in contrast to histological assessment. The main advantage of 'Raman biopsy' when compared with conventional histological analysis, is that it provides not only the morphological structure but also direct biochemical information. Indeed, a detailed inspection of Fig. 1f and $2 \mathrm{f}$ demonstrates the vibrations characteristic of various structures such as carotenoids, lipids, and proteins. Thus, Raman imaging plays an important role in the spectroscopic characterization of human breast tissues both from the tumor mass and from the margin.

A detailed inspection of Fig. If and $2 \mathrm{f}$ demonstrates that the areas from the tumor margin contain a markedly higher concentration of adipose tissue (triglycerides and fatty acids) than the cancerous tissue from the bulky tumor mass that is dominated by proteins. The Raman lipid profile characteristic of the adipose tissue (lipid (II) ${ }^{8}$ ) is dominated by peaks at 2854 , 2888 and $2926 \mathrm{~cm}^{-1}$ and is characteristic of unsaturated fatty acids and triglycerides. The peaks at 1004, 1158, and $1518 \mathrm{~cm}^{-1}$ correspond to vibrations typical of the $\mathrm{C}-\mathrm{C}$ and $\mathrm{C}=\mathrm{C}$ stretching modes of carotenoids. The Raman lipid-protein profile (lipid $(\text { II })^{8}$ ) characteristic of the cancerous tissue is dominated by the protein component, which is predominantly but not exclusively composed of type I collagen with typical vibrations of approximately $2940 \mathrm{~cm}^{-1}$. Collagen is the main structural protein of the various connective tissues to which the transformed epithelial cancer cells migrate and invade through the basement membrane. Additional proteins are produced by the organism in response to cancer development in the transformed epithelial cancer cells that migrate and invade through the basement membrane to the stroma. For example, approximately $30 \%$ of breast cancers exhibit an amplification of the HER2/neu gene or overexpression of its protein product. ${ }^{34}$

To monitor the accumulation of carotenoids and fatty acids in localized regions of the tissue, we have employed various spectral filters in the Raman images to analyze different areas of the breast tissues. Fig. 1d and 2d present the Raman images for the tissue from the tumor margin (Fig. 1d) and the cancerous tissue from the tumor mass (Fig. 2d) for the filters at approximately $1518 \mathrm{~cm}^{-1}$ (1490-1580 $\left.\mathrm{cm}^{-1}\right), 2854 \mathrm{~cm}^{-1}$ (2850-2950 $\left.\mathrm{cm}^{-1}\right)$, and $2940 \mathrm{~cm}^{-1}\left(2900-3010 \mathrm{~cm}^{-1}\right)$, corresponding to the vibrational frequencies of carotenoids, fatty acids and triglycerides, and proteins, respectively. One can observe that the Raman image of the adipose tissue in the breast tissue at the filter $1518 \mathrm{~cm}^{-1}$ (Fig. 1d and 2d) illustrates that the distributions of carotenoids is almost identical to that for the filter 2854 $\mathrm{cm}^{-1}$ for unsaturated fatty acids. This result clearly indicates that the adipose tissue acts as a dynamic reservoir that accumulates carotenoids to supply them to the human organs. In contrast, the cancerous breast tissue from the tumor mass does contain a very low amount of carotenoids, as demonstrated in Fig. $2 \mathrm{~d}$ at the filter $1518 \mathrm{~cm}^{-1}$. Additionally, the image at the protein filter at $2940 \mathrm{~cm}^{-1}$ in Fig. 2 d illustrates the distribution of proteins in the cancerous breast tissue. The comparison of the images of the cancerous tissue demonstrates that proteins are accumulated in the regions complementary to those of the fatty acids, triglycerides and carotenoids. The results obtained for the human tissue in this paper are consistent with those obtained in the previous papers. ${ }^{\mathbf{1 - 4}}$

Fig. 3 and 4 present the Raman images and typical Raman spectra of the breast tissues soaked in $\mathrm{AlPcS}_{4}$ aqueous solution $\left(c=10^{-6} \mathrm{M}\right)$ for the same areas and spectral regions as in Fig. 1 and 2. A detailed inspection of Fig. 3 and 4 reveals that the vibrations characteristic of carotenoids, fatty acids, and proteins are still easily visible in Raman spectra for the human breast tissue soaked in the photosensitizer $\mathrm{AlPcS}_{4}$ aqueous solution.

In addition, we can record the localization of photosensitizers using fluorescence images from the same areas as those obtained for the Raman images. Therefore, combining the Raman/fluorescence imaging, one can obtain information both on the localization of the photosensitizer and the biochemistry of the tissue structures where the photosensitizer is localized.

In this study, the wavelength of the source of irradiation did not correspond to the absorption maximum of the photosensitizer in aqueous solution. The absorption spectra of $\mathrm{AlPcS}_{4}$ in water solution and at the biological interface of the human breast tissues are presented in Fig. 5. The Soret band and the Qband are observed at $340 \mathrm{~nm}$ and at $678 \mathrm{~nm}$ in solution. The Qband $\left(\mathrm{S}_{0} \rightarrow \mathrm{S}_{1},\left(\mathrm{a}_{2 \mathrm{u}}\right) \rightarrow\left(\mathrm{e}_{\mathrm{g}}\right)\right.$ transition) in solution exhibits a sharp maximum at $678 \mathrm{~nm}$ as well as the weaker bands to the blue side, with maxima at $643 \mathrm{~nm}$ and at $607 \mathrm{~nm}$. We have demonstrated that the absorption of $\mathrm{AlPcS}_{4}$ is dominated by a monomeric form in aqueous solution. ${ }^{35}$ One can observe from Fig. 5 that in contrast to solutions, the absorption spectra at the biological interface of the tissues are represented by broad, structureless bands in the region of $500 \mathrm{~nm}$ to $800 \mathrm{~nm}$. Green light $(532 \mathrm{~nm})$ has been employed in this study because the absorption coefficient of $\mathrm{AlPcS}_{4}$ in the tissue at $532 \mathrm{~nm}$ is similar to that at the maximum of absorption at $670 \mathrm{~nm}$. This may be of clinical benefit in selected cases where lesions do not require significant illumination depth. ${ }^{11}$

Hydrophilic photosensitizers generally localize in lysosomes, ${ }^{21,36,37}$ and lipophilic dyes are concentrated in the plasma membrane, mitochondria, endoplasmic reticulum, and nuclear membranes. ${ }^{37}$ The AlPcS $_{4}$ is a hydrophilic and anionic photosensitizer.

One can observe in Fig. 6 that the $\mathrm{AlPcS}_{4}$ localizes predominantly in membrane structures of the adipose tissue (corresponding to the violet color in the fluorescence images in Fig. 6b) and in the epithelial cells spreading through the basement membrane of ducts into the supporting stroma (corresponding to the green color in the fluorescence images in Fig. 6b). The subcellular localization of the photosensitizer is related to interactions between hydrophilic $\mathrm{AlPcS}_{4}$ and proteins produced in the transformed epithelial cells. The photosensitizers did not accumulate in connective tissue, ${ }^{11}$ which is the predominant component of the stroma. As the hydrophilic photosensitizer, $\mathrm{AlPcS}_{4}$ molecules do not enter into the hydrophobic adipose tissue.

This preferential localization is even more visible in the breast tissue from the tumor mass in Fig. 7, where the photosensitizer is distributed exclusively in the infiltrating epithelial 
a)

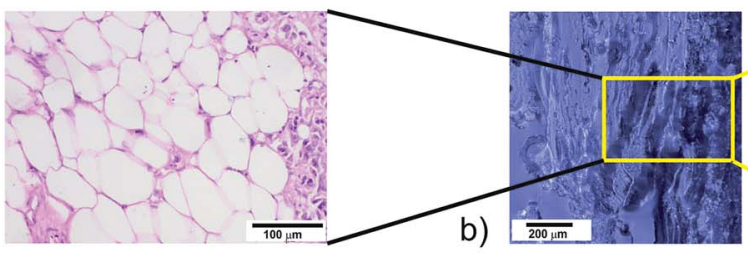

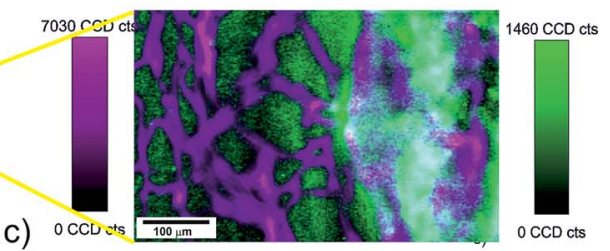

c)
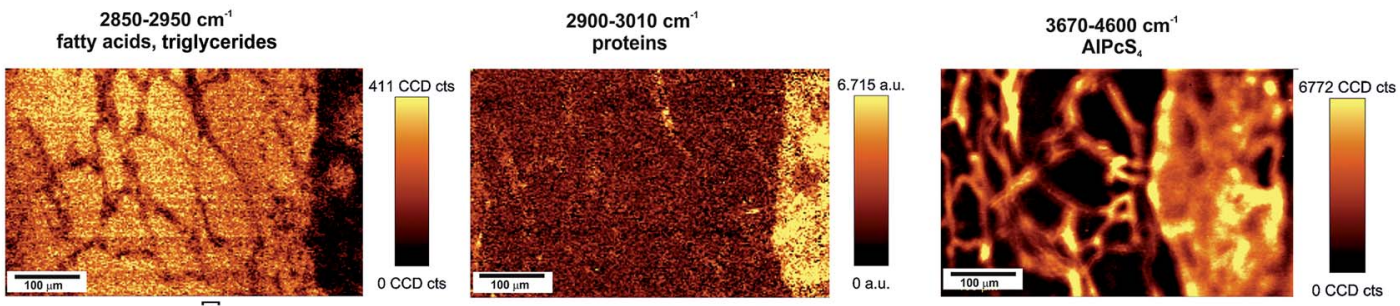

d)
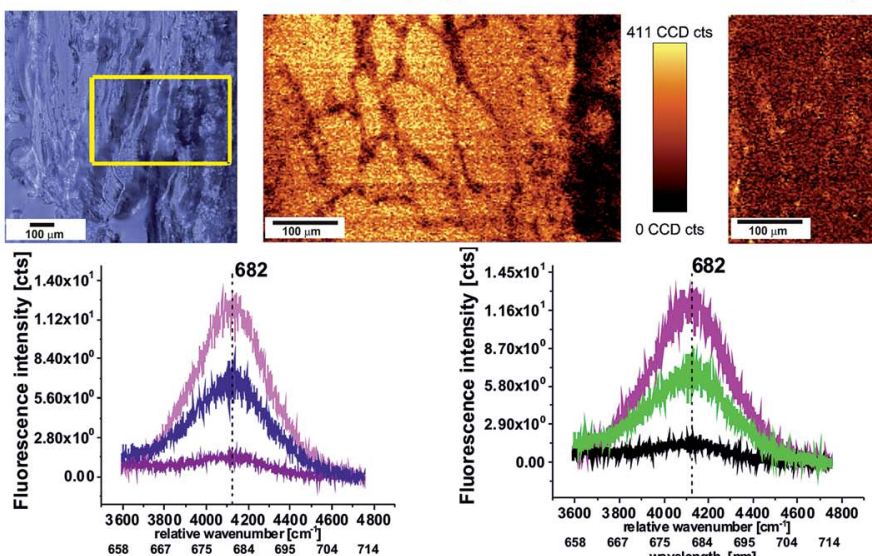

e)

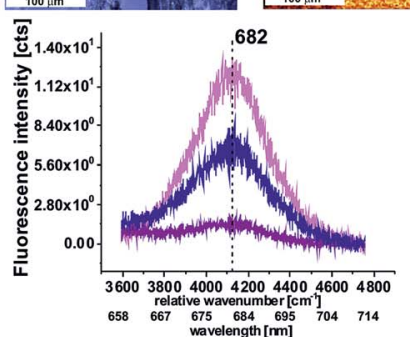

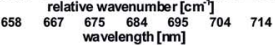

f)

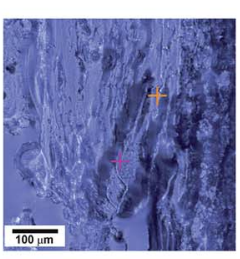

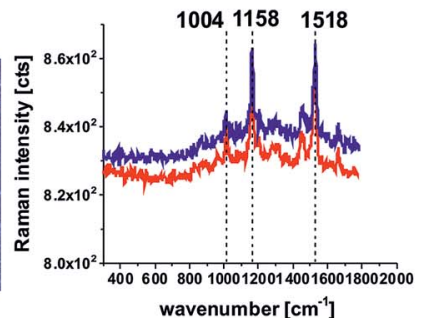
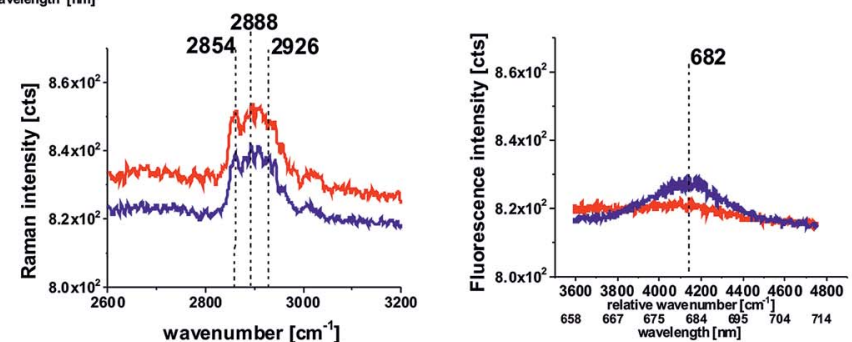

Fig. 3 Patient P104, the breast tissue from the margin of the tumor mass: H\&E-stained histological image (a), microscopy image $(1000 \times 1000$ $\mu \mathrm{m}, 2000 \times 2000$ pixels, spatial resolution $0.5 \times 0.5 \mu \mathrm{m})$ composed of 121 single video images (b), confocal/Raman fluorescence image (c), microscopy image $(1000 \times 1000 \mu \mathrm{m}, 2000 \times 2000$ pixels, spatial resolution $0.5 \times 0.5 \mu \mathrm{m})$ and images for the filters for spectral regions: $2850-$ $2950 \mathrm{~cm}^{-1}, 2900-3010 \mathrm{~cm}^{-1}$ and $3670-4600 \mathrm{~cm}^{-1}$ (d), average spectra used for the basis analysis method and single spectra corresponding to different areas of the fluorescence image (colors of the spectra corresponding to colors of the fluorescence/Raman image presented in part (c)) (e), and microscopy image $2000 \times 2000 \mu \mathrm{m}, 300 \times 300$ pixels, spatial resolution $(0.66 \times 0.66 \mu \mathrm{m})$ and single spectra of various sites of the sample, colors of the spectra correspond to the colors of the crosses in the microscopy image (f). Integration times: $0.3 \mathrm{~s}$ for Raman spectra and $0.1 \mathrm{~s}$ for fluorescence spectra.

cells in the supporting stroma (bright yellow areas) and is absent in the adipose tissue (dark circle areas at the bottom). The dark area at the top represents $\mathrm{CaF}_{2}$ support.

Fig. 6 and 7 demonstrate that the intensity of fluorescence decreases (photobleaching) with increasing fluence, which depends both on the increased power of the laser from $10 \mathrm{~mW}$ $\left(79 \mathrm{~J} \mathrm{~cm}^{-2}\right)$ to $40 \mathrm{~mW}\left(318 \mathrm{~J} \mathrm{~cm}^{-2}\right.$ ) (Fig. $6 \mathrm{~b}$ and $7 \mathrm{~b}$ ) and the duration of irradiation (Fig. $6 \mathrm{~b}$ and $7 \mathrm{~b}$ ). The loss of fluorescence simply indicates photodegradation of the photosensitizer during PDT. Direct observation of the fluorescence presented in Fig. 6 and 7 helps identify the optimal amount of the photosensitizer so as not to be completely bleached during PDT. Our results presented thus far demonstrate that the phthalocyanine level in normal tissue is much lower because it is dominated by adipose tissue, where the photosensitizer does not penetrate as readily as in the bulky tumor mass. Since the phthalocyanine level in normal tissue is much lower than that in tumors, it may be possible to choose the phthalocyanine dose at a level such that normal tissue is relatively undamaged, whereas the bulky tumor tissue is completely destroyed.

The comparison between both the histological and Raman images of the noncancerous and cancerous tissues demonstrates that the normal tissue contains markedly higher levels of adipose cells, which contains a high fraction of unsaturated fatty acids. This remark may suggest that the presence of the adipose tissue may be inversely related to breast cancer development. We have demonstrated that the lipid profile of the cancerous tissue differs from that of the noncancerous tissue and does not resemble the vibrational features of the unsaturated fatty acids. ${ }^{1-10}$ This observation, analyzed in the context of the present study and a number of literature studies, suggests that fatty acids and the products of their metabolism play an important role in the molecular mechanisms of carcinogenesis. ${ }^{3,36,38}$ In this context it is extremely important to monitor not 
a)

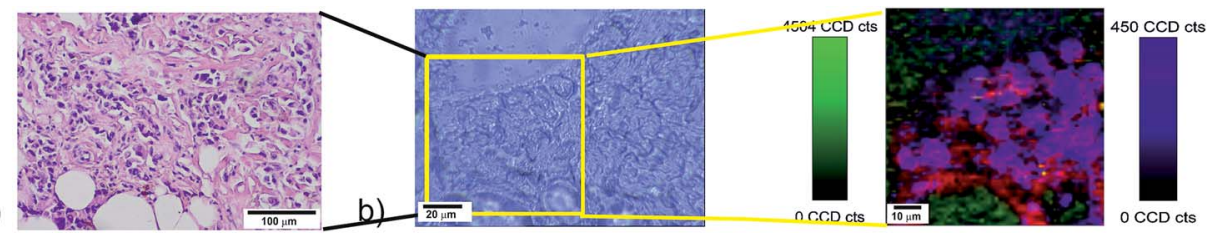

c)

d)
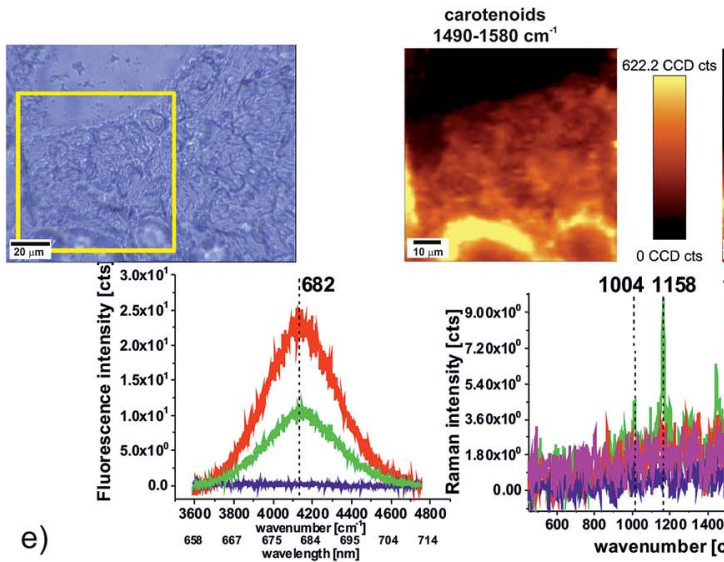
fatty acids, triglycerid
$2850-2950 \mathrm{~cm}^{-1}$

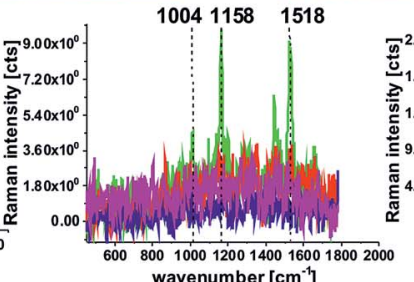

wavenumber $\left[\mathrm{cm}^{-1}\right]$
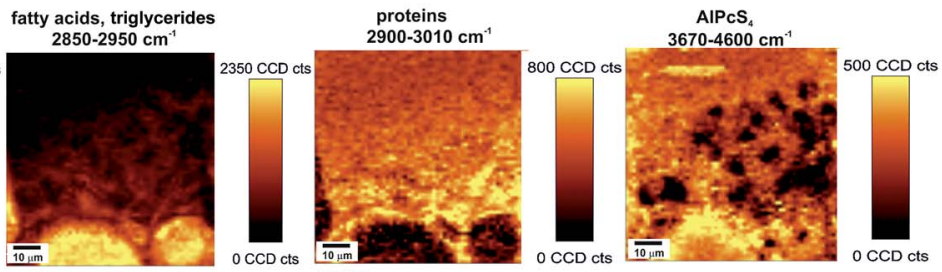

Fig. 4 Patient P104, the breast tissue from the tumor mass: H\&E-stained histological image (a), microscopy image $(100 \times 80 \mu \mathrm{m}, 60 \times 60$ points per line, resolution $1.3 \times 1.3 \mu \mathrm{m})(\mathrm{b})$, confocal fluorescence/Raman image $(80 \times 80 \mu \mathrm{m}, 60 \times 60$ points per line, resolution $1.3 \times 1.3 \mu \mathrm{m})(\mathrm{c})$, microscopy image $(100 \times 80 \mu \mathrm{m}, 60 \times 60$ points per line, resolution $1.3 \times 1.3 \mu \mathrm{m})$, images for the filters for spectral regions: $1490-1580 \mathrm{~cm}^{-1}$, $2850-2950 \mathrm{~cm}^{-1}, 2900-3010 \mathrm{~cm}^{-1}$, and $3670-4600 \mathrm{~cm}^{-1}(\mathrm{~d})$, and average spectra used for the basis analysis method and single spectra corresponding to different areas of the fluorescence image (colors of the spectra corresponding to colors of the Raman image presented in part (c)) (e). Integration time: $0.3 \mathrm{~s}$ for Raman spectra and $0.1 \mathrm{~s}$ for fluorescence spectra.

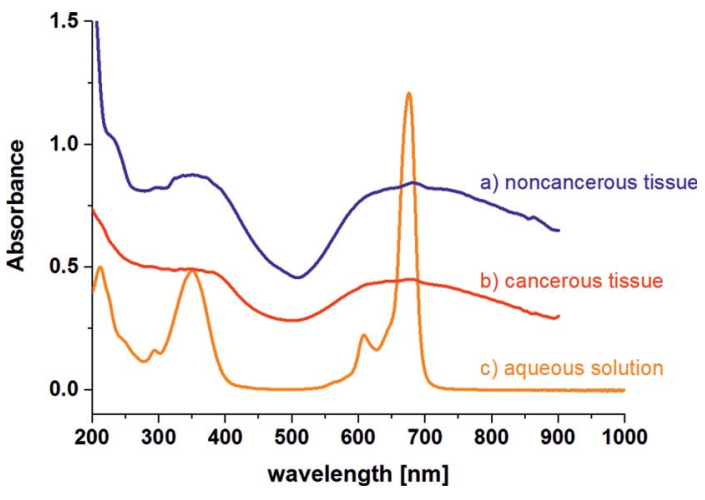

Fig. 5 Absorption spectra of $\mathrm{AlPcS}_{4}$ in noncancerous (a), cancerous (b), and water solution $c=10^{-4} \mathrm{M}$ (c).

only the photodegradation of the photosensitizer, but also to control biodegradation of the main constituents of the tissue upon PDT irradiation.

The comparison between the fluorescence images and Raman images will help to answer these questions. One can see from the comparison between the Raman image presented in Fig. 6a and the fluorescence image in Fig. $6 c$ that the extent of damage to the cellular membranes induced by PDT in vitro appears to be small when one monitors the morphology of the tissue structures. It indicates that the PDT damage is not as overwhelming as in necrosis, where the abrupt disruption of cellular membranes is expected.
Now, more detailed analyses of the damage in various biochemical components in the cells will be considered.

Fig. 8 presents the single Raman spectrum of carotenoids from the same position of the sample after irradiation with $79 \mathrm{~J} \mathrm{~cm}^{-2}$ and after irradiation with another dose of $318 \mathrm{~J} \mathrm{~cm}^{-2}$ followed by an additional dose of $79 \mathrm{~J} \mathrm{~cm}^{-2}$ of breast tissue from the tumor mass. One can observe that the Raman intensity of carotenoids does not change dramatically.

Fig. 9 presents the single Raman spectrum of lipids in the adipose tissue from the same position of the sample after irradiation with $79 \mathrm{~J} \mathrm{~cm}^{-2}$ and after irradiation with another dose of $318 \mathrm{~J} \mathrm{~cm}^{-2}$ followed by an additional dose of $79 \mathrm{~J} \mathrm{~cm}^{-2}$. One can observe that the Raman intensity of lipids changes significantly during the PDT process by about $50 \%$.

Fig. 10 presents the single Raman spectrum of proteins from the same position of the sample after irradiation with $79 \mathrm{~J} \mathrm{~cm}^{-2}$ and after irradiation with another dose of $318 \mathrm{~J} \mathrm{~cm}^{-2}$ followed by an additional dose of $79 \mathrm{~J} \mathrm{~cm}^{-2}$. One can observe that the Raman intensity of proteins changes dramatically after irradiation and decreases by $50 \%$ which indicates that damage is severe although not as overwhelming as in necrosis, where the abrupt disruption of cellular membranes is expected.

\section{Experimental}

\section{Patients and samples}

We examined human breast cancer specimens (infiltrating ductal carcinoma). The breast tissue samples were obtained 
a)

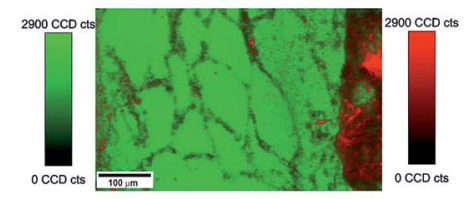

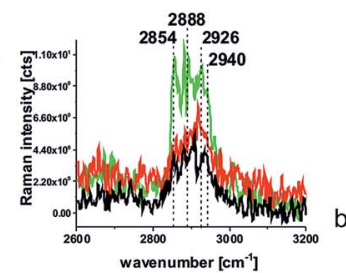
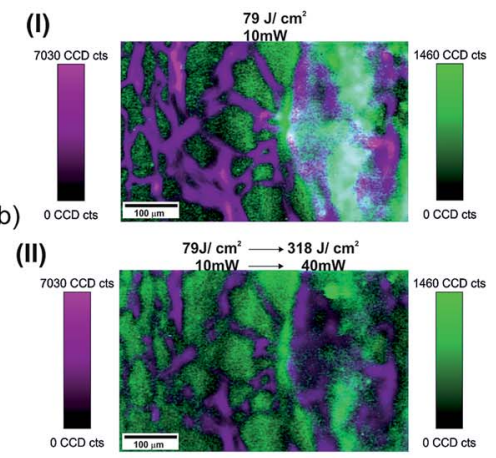

$79 \mathrm{~J} / \mathrm{cm}^{2} \longrightarrow 318 \mathrm{~J} / \mathrm{cm}^{2}$

(III) $79 \mathrm{~J} / \mathrm{cm}^{2} \rightarrow 318 \mathrm{~J} / \mathrm{cm}^{2} \rightarrow 79 \mathrm{~J} / \mathrm{cm}^{2}$

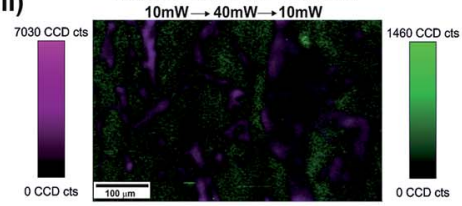

c)
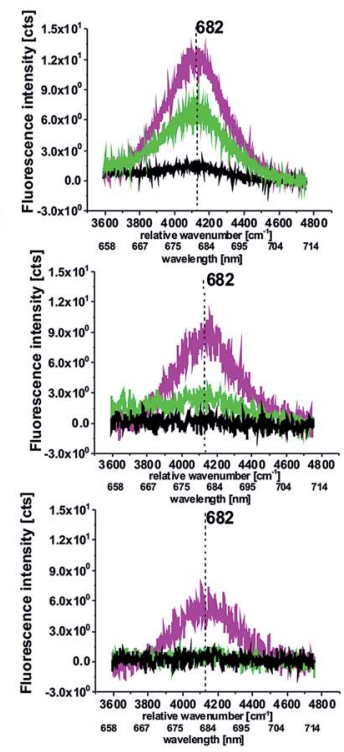

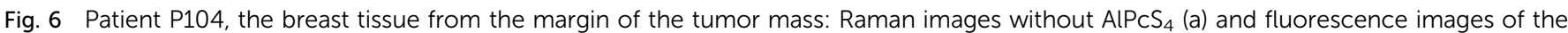
tissue soaked in AlPcS $_{4}$ and irradiated with doses: $79 \mathrm{~J} \mathrm{~cm}^{-2}$ (I), followed by the next $318 \mathrm{~J} \mathrm{~cm}^{-2}$ (II) and $79 \mathrm{~J} \mathrm{~cm}$ (III) (b) and the fluorescence spectra of $\mathrm{AlPcS}_{4}$ (c). The colors of the fluorescence spectra correspond to the colors of the fluorescence images (b). Integration time: $0.1 \mathrm{~s}$.
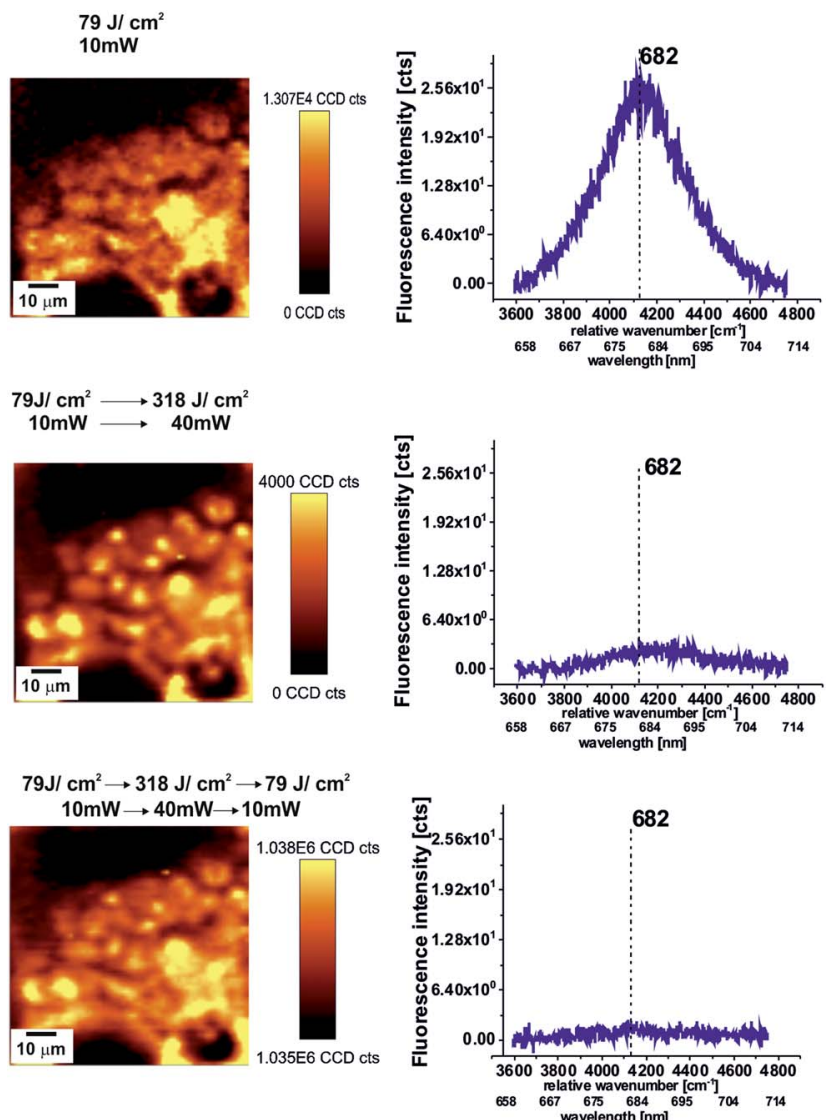

Fig. 7 Fluorescence images $(80 \times 80 \mu \mathrm{m}, 60 \times 60$ points per line, spatial resolution $1.3 \times 1.3 \mu \mathrm{m}$ ) from the spectral region $3670-4600$ $\mathrm{cm}^{-1}$ of the tissue from the tumor mass soaked in $\mathrm{AlPcS}_{4}$ irradiated using doses: $79 \mathrm{~J} \mathrm{~cm}^{-2}$, followed by the next $318 \mathrm{~J} \mathrm{~cm}^{-2}$ and $79 \mathrm{~J} \mathrm{~cm}^{-2}$ and the Raman spectra of $\mathrm{AlPcS}_{4}$ from the bright yellow areas. Integration time: $0.1 \mathrm{~s}$. during a surgical operation. The research did not affect the course of the operation or treatment of the patients.

To visualize and identify tissue structures through Raman imaging, we developed a method for processing the surgical specimens. First, we assessed the effects of the standard steps in the histology protocols, such as formalin fixation, paraffinembedding, and coating to adhere the cover glass to the microscope slide, on Raman measurements. We observed that using the standard chemical fixative to preserve the tissue from degradation, i.e., 10\% neutral-buffered formalin (4\% formaldehyde in phosphate-buffered saline), did not introduce essential changes in the Raman spectra. This conclusion is based on a comparison between the results obtained using fresh tissue samples (167 patients) and those obtained using formalin-fixed tissue samples ( 55 patients). In contrast, paraffin embedding was not an appropriate protocol for use in Raman measurements. The paraffinization protocol contains steps, such as alcohol dehydration, xylene clearance, and paraffin wax infiltration and embedding that might introduce artifacts in Raman spectra. We observed that the use of frozen sections (cryosectioned samples), in which the frozen fresh tissue (or formalin-fixed tissue) is sliced into thin sections ( $6 \mu \mathrm{m}$ and 16 $\mu \mathrm{m})$ using a microtome (Microm HM 550, Sermed), is the most appropriate protocol for Raman measurements. The fresh tissue obtained during surgery was snap frozen in liquid nitrogen. The frozen blocks of fresh tissue were stored at $-80{ }^{\circ} \mathrm{C}$ until further processing. In most cases, the samples were used within a few hours from preparation. The process similar to bread loafing has been employed to cut the surgical specimens into 4 or more sections from the tumor mass and from the safety margins of the excised tumor where no carcinoma was detected by the histopathologists. The frozen tissue was cut into thin sections at $-25{ }^{\circ} \mathrm{C}$ for unfixed tissue. The thin, adjacent 

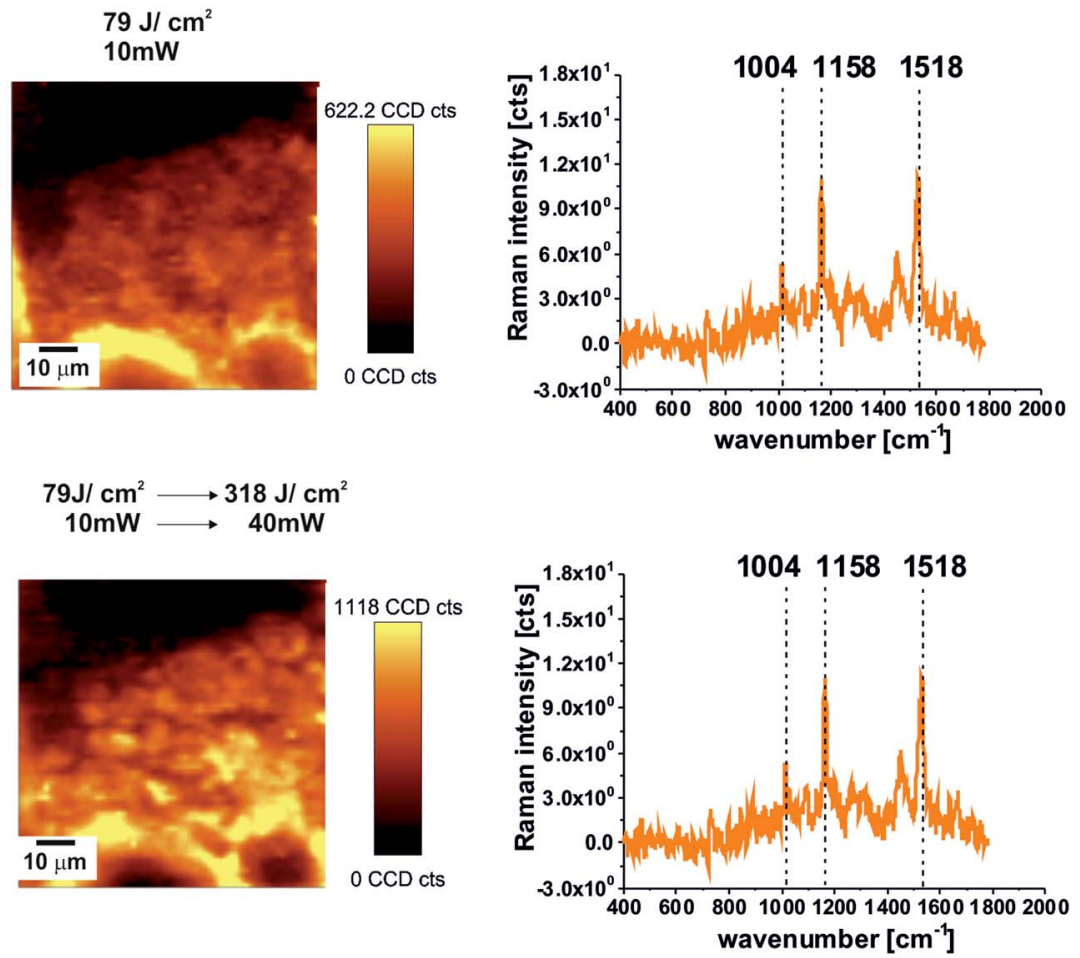

$79 \mathrm{~J} / \mathrm{cm}^{2} \rightarrow 318 \mathrm{~J} / \mathrm{cm}^{2} \rightarrow 79 \mathrm{~J} / \mathrm{cm}^{2}$ $10 \mathrm{~mW} \rightarrow 40 \mathrm{~mW} \rightarrow 10 \mathrm{~mW}$
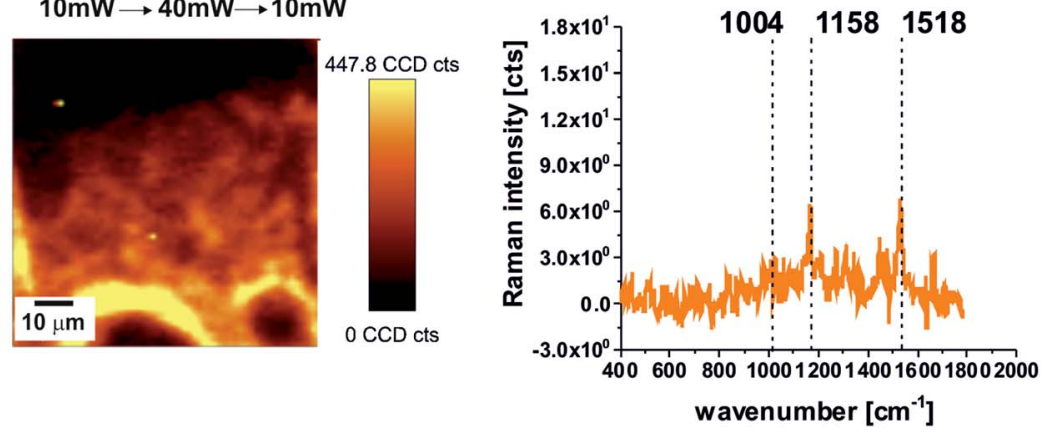

Fig. 8 Raman images $(80 \times 80 \mu \mathrm{m}, 60 \times 60$ points per line, spatial resolution $1.3 \times 1.3 \mu \mathrm{m})$ from the spectral region $1490-1580 \mathrm{~cm}^{-1} \mathrm{of}$ the cryosectioned breast tissue from the tumor mass soaked in $\mathrm{AlPcS}_{4}$ and irradiated using doses: $79 \mathrm{~J} \mathrm{~cm}^{-2}$, followed by the next $318 \mathrm{~J} \mathrm{~cm}{ }^{-2}$ and 79 $\mathrm{J} \mathrm{cm}{ }^{-2}$ as well as the Raman spectra of $\mathrm{AlPcS}_{4}$ from the bright yellow areas.

sections represent the same breast structures and the same type of pathology. The thin slices without staining were mounted on $\mathrm{CaF}_{2}$ windows for Raman/fluorescence and UV-Vis absorption measurements. For both Raman/fluorescence measurements, the tissue specimens were not covered with another layer of glass attached to the sample, as this adhesive introduces artifacts due to the vibrational spectra of the adhesive in the same spectral range as the lipids of the tissue.

The adjacent sections of tissue were mounted on glass slides, stained with hematoxylin and eosin and covered with another layer of glass using a specific adhesive (Histokitt, Glaswarenfabrik Karl Hecht GmbH \& Co KG, CAS: 1330-20-7) for histological examination. After obtaining the Raman measurements, trained pathologists examined and stained the slices. As the quality of the slides produced from the frozen sections was lower than that obtained in the standard procedure, standard histology processing using wax-embedded tissue was additionally performed to obtain a more accurate diagnosis for each patient. ${ }^{32}$ Professional medical doctors, a board certified as pathologists, from the Medical University of Lodz, Department of Pathology, Chair of Oncology performed and analyzed the histological images.

After the Raman/fluorescence measurements (spectra and images), the samples of the cancerous and the noncancerous breast tissues were stained with aqueous solutions of aluminum tetrasulfonated phthalocyanine $\left(c=10^{-6} \mathrm{M}\right)$. The concentration corresponds to the typical concentrations used in cytotoxicity measurements of cell cultures, ranging from 1 to 10 $\mu \mathrm{g} \mathrm{ml}{ }^{-1},{ }^{39}$ and in clinical applications (current standard for Photofrin of $\left.2 \mathrm{mg} \mathrm{kg}^{-1}\right) .{ }^{11}$ The Raman/fluorescence images were recorded from the same area as without staining. 

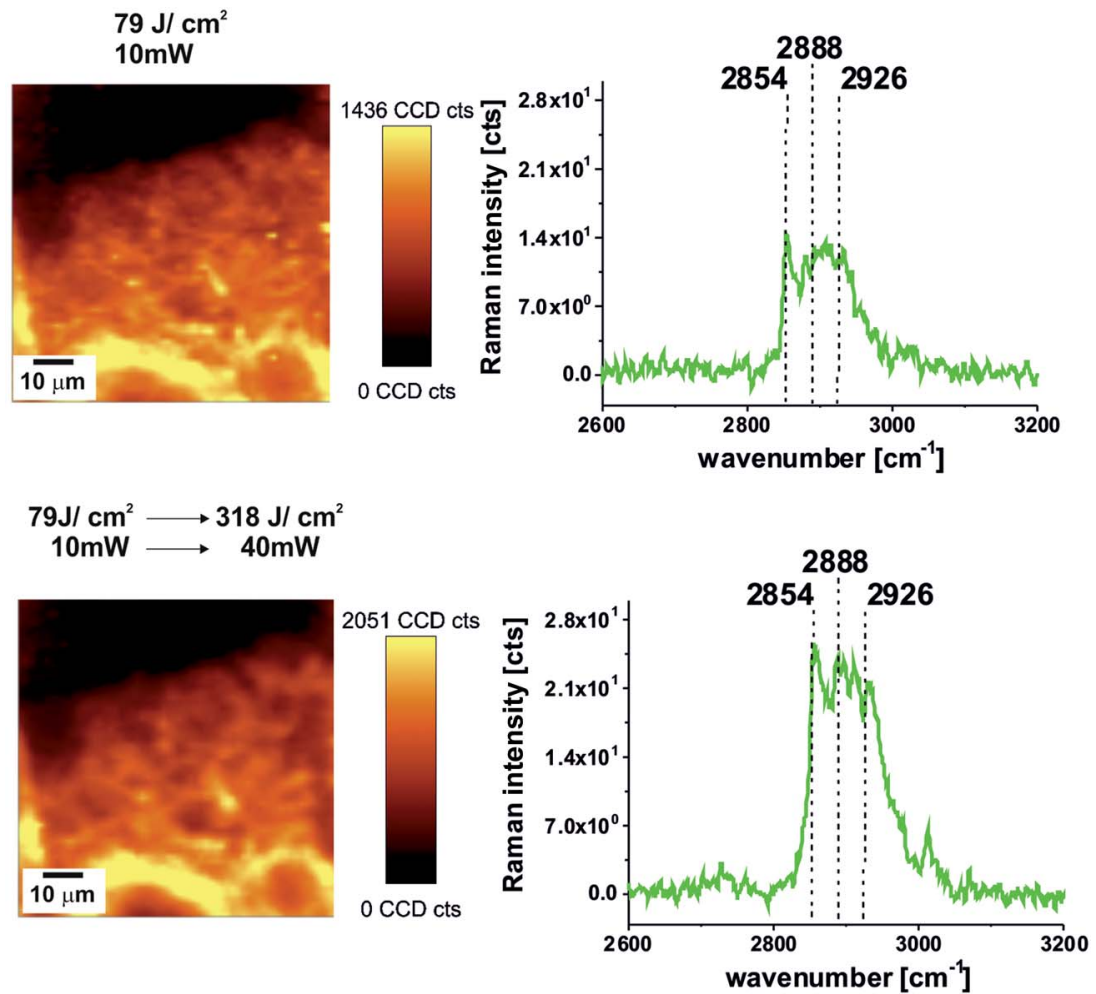

$79 \mathrm{~J} / \mathrm{cm}^{2} \rightarrow 318 \mathrm{~J} / \mathrm{cm}^{2} \rightarrow 79 \mathrm{~J} / \mathrm{cm}^{2}$ $10 \mathrm{~mW} \rightarrow 40 \mathrm{~mW} \rightarrow 10 \mathrm{~mW}$
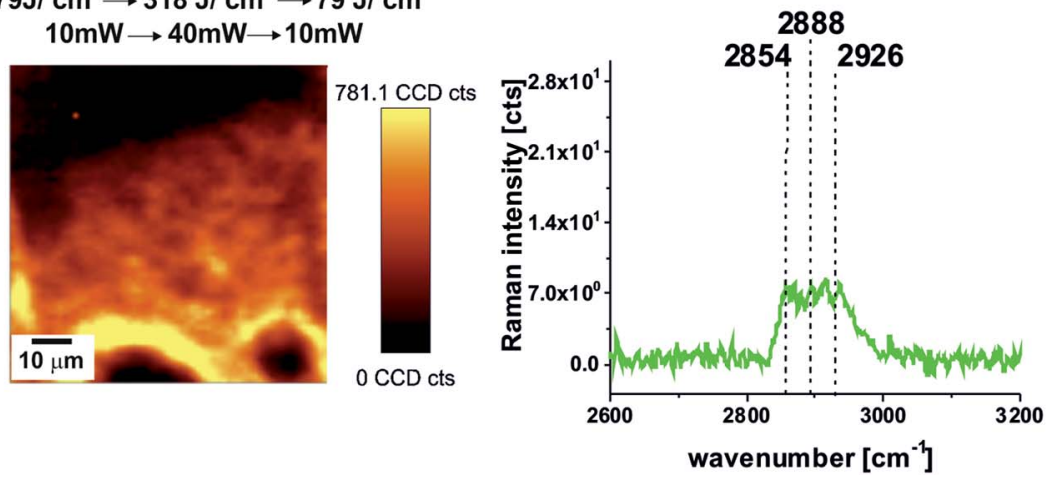

Fig. 9 Raman images $(80 \times 80 \mu \mathrm{m}, 60 \times 60$ points per line, spatial resolution $1.3 \times 1.3 \mu \mathrm{m})$ from the spectral region $2850-2950 \mathrm{~cm}^{-1}$ of the breast tissue from the tumor mass soaked in AlPcS 4 and using doses: $79 \mathrm{~J} \mathrm{~cm}^{-2}$, followed by the next $318 \mathrm{~J} \mathrm{~cm}^{-2}$ and $79 \mathrm{~J} \mathrm{~cm}{ }^{-2}$ as well as the Raman spectra of lipid region from the bright yellow areas.

\section{Aluminum phthalocyanine}

Aluminum tetrasulfonated phthalocyanine (aluminum phthalocyanine chloride tetrasulphonic acid) was purchased from Frontier Scientific, Inc. (AlPcS-834). Aluminum tetrasulfonated phthalocyanine was used without further purification. Water was deionized before preparing the solutions.

\section{Instrumentation}

Raman/fluorescence microspectroscopy and imaging. Raman spectra and images were obtained with an alpha 300 RA (WITec, Ulm, Germany) model equipped with an Olympus microscope coupled via the fiber of a $25 \mu \mathrm{m}$ core diameter to an UHTS (Ultra High Throughput Spectrometer) spectrometer and a CCD Camera Andor Newton DU970N-UVB-353 operating in standard mode with $1600 \times 200$ pixels at $-60{ }^{\circ} \mathrm{C}$ with full vertical binning. The incident laser beam (doubled SHG of the Nd:YAG laser (532 nm)) of alpha $300 \mathrm{RA}$ was focused on the sample through a $40 \times$ dry objective (Nikon, objective type CFI Plan Fluor C ELWD DIC-M, numerical aperture (NA) of 0.60 and a 3.6-2.8 $\mathrm{mm}$ working distance) to the spot of $200 \mathrm{~nm}$. The average laser excitation power was $10 \mathrm{~mW}$, with an integration time of $0.3 \mathrm{~s}$ (Raman imaging) and $0.1 \mathrm{~s}$ (fluorescence imaging). Rayleigh scattered light was removed using an edge filter. The samples were irradiated by a laser at $532 \mathrm{~nm}$ at a dose $79 \mathrm{~J} \mathrm{~cm}^{-2}$ (fluorescence imaging) and $318 \mathrm{~J} \mathrm{~cm}^{-2}$ (Raman imaging). The light dose of $79 \mathrm{~J} \mathrm{~cm}^{-2}$ corresponds to the doses typical for phototoxicity measurements of cell cultures, ${ }^{11}$ and light doses lower than $100 \mathrm{~J} \mathrm{~cm}^{-2}$ for clinical applications have obtained FDA approval. ${ }^{13}$ 

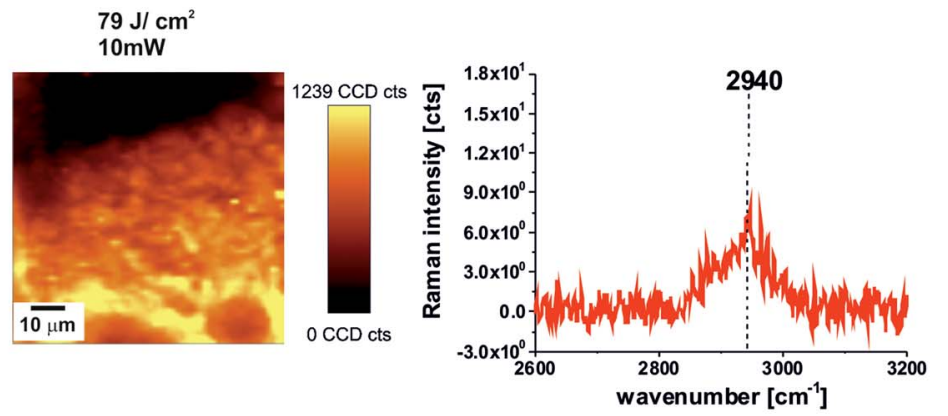

$$
\overline{10 \mu \mathrm{m}}
$$
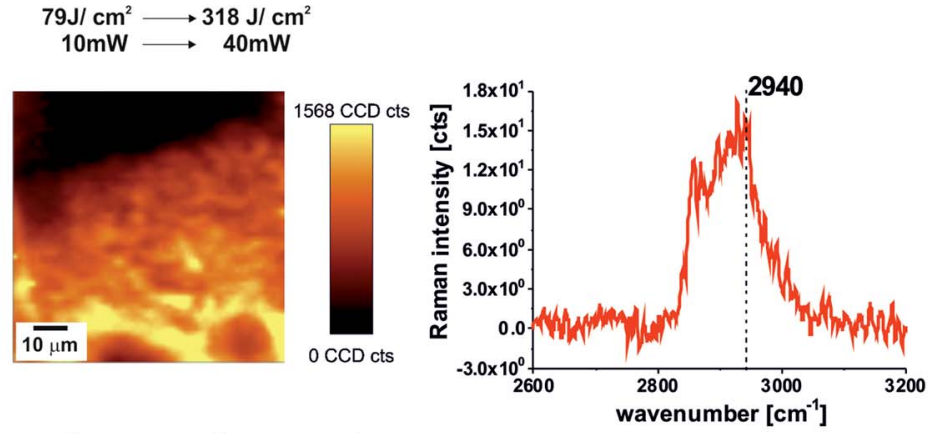

$\overline{10 \mu \mathrm{m}}$

$79 \mathrm{~J} / \mathrm{cm}^{2} \rightarrow 318 \mathrm{~J} / \mathrm{cm}^{2} \rightarrow 79 \mathrm{~J} / \mathrm{cm}^{2}$

$10 \mathrm{~mW} \rightarrow 40 \mathrm{~mW} \rightarrow 10 \mathrm{~mW}$
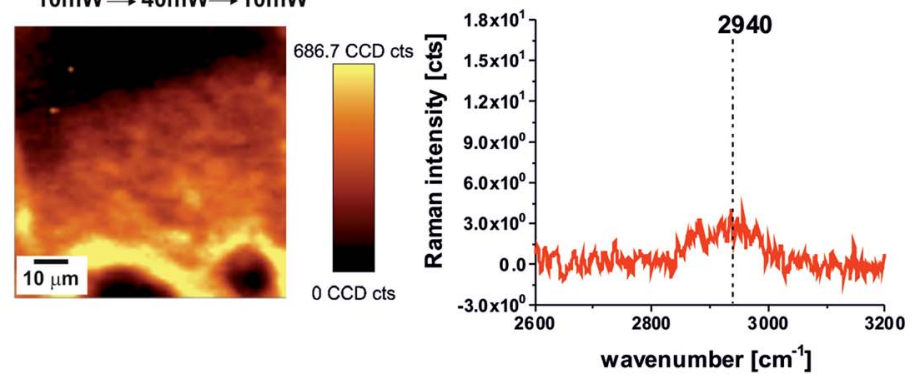

$\overline{10 \mu \mathrm{m}}$

Fig. 10 Raman images $(80 \times 80 \mu \mathrm{m}, 60 \times 60$ points per line, spatial resolution $1.3 \times 1.3 \mu \mathrm{m})$ from the spectral region $2900-3010 \mathrm{~cm}^{-1}$ of the tissue soaked in $\mathrm{AlPcS}_{4}$ and irradiated with doses: $79 \mathrm{~J} \mathrm{~cm}^{-2}$, followed by the next $318 \mathrm{~J} \mathrm{~cm}^{-2}$ and $79 \mathrm{~J} \mathrm{~cm}^{-2}$ as well as the Raman spectra of $\mathrm{AlPcS}_{4}$ from the bright yellow areas.

A piezoelectric table was used to record Raman images. Spectra were collected at one acquisition per pixel and 1200 lines per $\mathrm{mm}$ diffraction grating. Prior to the basis analysis, each spectrum was processed to remove cosmic rays, increase the signal-to-noise ratio via spectral smoothing (Savitzky-Golay method), subtract a baseline arising from the $\left(\mathrm{CaF}_{2}\right)$ substrate and correct for biological autofluorescence. The large number of spectra collected in this study required the use of an automated removal method for all of the spectra, which is critical to remove sources of variability arising from autofluorescence and substrate contamination. After baseline removal, the dominant remaining source of distinction between spectra is the intensity of the Raman features, arising from the variable amount of biological material within the sample. Data acquisition and processing were performed using WITec Project 2.10. The 2D array images of tens of thousands of individual Raman spectra were evaluated by the basis analysis method. In this method, each measured spectrum of the 2D spectral array is compared to basis spectra using a least squares fit. Such basis spectra are created as the average spectra from three different areas in the sample. The weight factor at each point is represented as a $2 \mathrm{D}$ image of the corresponding color and mixed coloring component. The color code of Raman maps was based on the integrated Raman intensities in specific regions (sum option in the filter manager in the Witec project Plus 2.10). Using a lookup table, bright yellow colors indicate the highest intensities, whereas brown colors indicate the lowest intensities of the chosen region.

Vis-UV and IR absorption measurements. Vis-UV absorption spectra of $\mathrm{AlPcS}_{4}$ in aqueous solution $\left(c=10^{-4} \mathrm{M}\right)$ and in human breast tissues at room temperature were recorded using a Cary $5 \mathrm{E}$ (Varian) spectrometer.

IR spectra were recorded using a Specord M 80 (Germany). Specord M80 is a double-beam spectrometer for the measurement of lead 4000 to $200 \mathrm{~cm}^{-1}(2.5-50 \mu \mathrm{m})$ with an accuracy ranging from $\pm 0.8 \mathrm{~cm}^{-1}$ to $\pm 0.3 \mathrm{~cm}^{-1}$, depending on the spectral range. The spectra were scanned with $4 \mathrm{~cm}^{-1}$ step and recorded in an $800-4000 \mathrm{~cm}^{-1}$ range at $293 \mathrm{~K}$. 


\section{Conclusions}

Raman microspectroscopy and confocal Raman imaging combined with confocal fluorescence were used to study the distribution of aluminum tetrasulfonated phthalocyanine $\left(\mathrm{AlPcS}_{4}\right)$ in noncancerous and cancerous breast tissues. The study has illustrated important aspects of the use of the $\mathrm{AlPcS}_{4}$ photosensitizer in PDT of human breast tissue by Raman/fluorescence imaging. We have presented the Raman spectra and Raman/fluorescence images of noncancerous and cancerous human breast tissues as well as the results for tissues stained with the $\mathrm{AlPcS}_{4}$. The results are very promising and demonstrate that the combined Raman/fluorescence imaging exhibits great potential for photodynamic therapy, monitoring the distribution of photosensitizers, and the biochemical distribution of tissue components. The results demonstrate the ability of Raman/fluorescence imaging to distinguish between noncancerous and cancerous human breast tissue and to identify differences in the distribution of aluminum tetrasulphonated phthalocyanine in normal and cancerous tissue. Raman/fluorescence imaging monitors both the localization of photosensitizers and the distribution of constituents of cells, providing information on the morphology and biochemistry of tissue structures. We have observed that the distribution of aluminum tetrasulfonated phthalocyanine confined in cancerous human breast tissue is markedly different from that in noncancerous tissue. We have found that the $\mathrm{AlPcS}_{4}$ photosensitizer localizes predominantly in membranes of the adipose tissue in the normal breast noncancerous areas of tissue and in the epithelial cells spreading through the basement membrane of ducts into the supporting stroma in the cancerous tissue.

We monitored the loss of fluorescence of the $\mathrm{AlPcS}_{4}$ which simply indicates photodegradation of the photosensitizer during PDT irradiation. Direct observation of the fluorescence helps identify the optimal amount of photosensitizer so as not to be completely bleached during PDT. We obtained an irradiation dose of $318 \mathrm{~J} \mathrm{~cm}^{-2}$ which leads to complete photodegradation of the $\mathrm{AlPcS}_{4}$ at the concentration $c=10^{-6} \mathrm{M}$ corresponding to the typical concentrations used in cytotoxicity measurements of cell cultures and in clinical applications.

Our results demonstrate that the phthalocyanine level in normal breast tissue is much lower because it is dominated by adipose tissue, where the photosensitizer does not penetrate as readily as in the bulky tumor mass. Since the phthalocyanine level in normal tissue is much lower than that in tumors, it is possible to choose the phthalocyanine dose at a level such that normal tissue is relatively undamaged, whereas the bulky tumor tissue is completely destroyed.

We have monitored not only the photodegradation of the photosensitizer, but also the biodegradation of the main constituents of the tissue upon PDT irradiation. We have found that the Raman intensity of lipids and proteins changes dramatically after irradiation and decreases by $50 \%$ at doses higher than $78 \mathrm{~J} \mathrm{~cm}^{-2}$ which indicates that the PDT damage is severe although not as overwhelming as in necrosis, where abrupt disruption of cellular membranes is expected.
We conclude that Raman imaging can be treated as a new and powerful technique in the photodynamic therapy of cancer, increasing our knowledge of the mechanisms and efficiency of photosensitizers by better monitoring the localization in cancer cells and through the clinical assessment of the therapeutic effects of PDT and PIT.

\section{Acknowledgements}

The research work has been financed from the National Science Center of Poland-NCN grant UMO-2012/07/B/ST4/01588 and Dz. St. 2014.

\section{Notes and references}

1 H. Abramczyk and B. Brozek-Pluska, Chem. Rev., 2013, 113, 5766-5781.

2 J. Surmacki, J. Musiał, R. Kordek and H. Abramczyk, Mol. Cancer, 2013, 12, 48, DOI: 10.1186/1476-4598-12-48.

3 B. Brozek-Pluska, J. Musial, R. Kordek, E. Bailo, T. Dieing and H. Abramczyk, Analyst, 2012, 137, 3773-3780.

4 H. Abramczyk, B. Brozek-Pluska, J. Surmacki, J. JablonskaGajewicz and R. Kordek, Prog. Biophys. Mol. Biol., 2012, 108, 74-81.

5 B. Brozek-Pluska, A. Jarota, J. Jablonska-Gajewicz, R. Kordek, W. Czajkowski and H. Abramczyk, Technol. Cancer Res. Treat., 2012, 4, 317-331.

6 B. Brozek-Pluska, J. Jablonska-Gajewicz, R. Kordek and H. Abramczyk, J. Med. Chem., 2012, 54, 3386-3392.

7 H. Abramczyk, B. Brozek-Pluska, J. Surmacki, J. JablonskaGajewicz and R. Kordek, J. Biophys. Chem., 2011, 2, 158-169.

8 H. Abramczyk, B. Brozek-Pluska, J. Surmacki, J. Jablonska and R. Kordek, J. Mol. Liq., 2011, 164, 123-131.

9 H. Abramczyk, J. Surmacki, B. Brożek-Płuska, Z. Morawiec and M. Tazbir, J. Mol. Struct., 2009, 924-926, 175-182.

10 H. Abramczyk, I. Placek, B. Brożek-Płuska, J. Surmacki, K. Kurczewski, Z. Morawiec and M. Tazbir, Spectros. Int. J, 2008, 22, 16-21.

11 R. R. Allison and K. Moghissi, Photodiagn. Photodyn. Ther., 2013, 10, 331-341.

12 S. Yano, S. Hirohara, M. Obata, Y. Hagiya, S. Ogura, A. Ikeda, H. Kataoka, M. Tanaka and T. Joh, J. Photochem. Photobiol., C, 2011, 12, 46-67.

13 A. Juzeniene and J. Moan, Photodiagn. Photodyn. Ther., 2007, 4, 3-11.

14 A. P. Castano, T. N. Demidova and M. R. Hamblin, Photodiagn. Photodyn. Ther., 2004, 1, 279-293.

15 W. M. Sharman, J. E. van Lier and C. M. Allen, Adv. Drug Delivery Rev., 2004, 56, 3-76.

16 M. Mitsunaga, M. Ogawa, N. Kosaka, L. T. Rosenblum, P. L. Choyke and H. Kobayashi, Nat. Med., 2011, 17, 16851691.

17 L. Milla Sanabria, M. Rodríguez, I. Cogno, N. Rumie Vittar, M. Pansa, M. Lamberti and V. Rivarola, Biochim. Biophys. Acta Rev. Canc., 2013, 1835, 36-45. 
18 M. R. Hamblin and P. Mróz, Advances in Photodynamic Therapy: Basic, Translational and Clinical, Artech House, Boston, London, 2008, pp. 1-12.

19 B. W. Henderson and T. J. Dougherty, Photochem. Photobiol., 1992, 55(1), 145-157.

20 N. Kobayashi and A. B. P. Lever, J. Am. Chem. Soc., 1987, 109, 7433-7441.

21 A. R. Kane, J. F. Sullivan, D. H. Kenny and M. E. Kenney, Inorg. Chem., 1987, 9, 1445-1448.

22 S. Dhami, J. J. Cosa, S. M. Bishop and D. Phillips, Langmuir, 1996, 12, 293-300.

23 E. Ben-Hur, T. M. A. R. Dubbelman and J. Van Steveninck, Photochem. Photobiol., 1991, 54(2), 163-166.

24 Y. Cheng, A. C. Samia, J. D. Meyers, I. Panagopoulos, B. Fei and C. Burda, J. Am. Chem. Soc., 2008, 130, 10643-10647.

25 S. Herrwerth, T. Rosendahl, C. Feng, J. Fick, W. Eck, M. Himmelhaus, R. Dahint and M. Grunze, Langmuir, 2003, 19, 1880-1887.

26 J. Chen, D. Wang and J. Xi, Nano Lett., 2007, 7, 1318-1322.

27 X. Huang, W. Qian, I. H. El-Sayed and M. A. El-Sayed, Lasers Surg. Med., 2007, 39, 747-775.

28 M. E. Wieder, D. C. Hone, M. J. Cook, M. M. Handsley, J. Gavrilovic and D. A. Russell, Photochem. Photobiol. Sci., 2006, 5, 727-734.

29 C. Hone, P. I. Walker, R. Evans-Gowing, S. FitzGerald, A. Beeby, I. Chambrier, M. J. Cook and D. A. Russel, Langmuir, 2002, 18, 2985-2987.
30 M. Camerin, M. Magaraggia, M. Soncin, G. Jori, M. Moreno, I. Chambrier, M. J. Cook and D. A. Russell, Eur. J. Cancer, 2010, 46, 1910-1918.

31 T. Stuchinskaya, M. Moreno and M. C. Cook, Photochem. Photobiol. Sci., 2011, 10, 822-831.

32 Sigma-Aldrich Mayers Hämatoxylin-Lösung Verfahrens Nr. MHS AR-MED Ltd., 2003.

33 K. Hartmann, M. Becker-Putsche, T. Bocklitz, K. Pachmann, A. Niendorf, P. Rösch and J. Popp, Anal. Bioanal. Chem., 2012, 403, 745-753.

34 J. A. Menendez, L. Vellon, R. Colomer and R. Lupu, Ann. Oncol., 2005, 16, 359-371.

35 A. Jarota, M. Tondusson, G. Galle, E. Freysz and H. Abramczyk, J. Phys. Chem. A, 2012, 116, 4000-4009.

36 A. Soto-Guzman, N. Navarro-Tito, L. Castro-Sanchez, R. Martinez-Orozco and E. P. Salazar, Clin. Exp. Metastasis, 2010, 27, 505-515.

37 J. Moan, T. Christensen and S. Sommer, Cancer Lett., 1982, 15, 161-166.

38 G. Mamalakis, C. Hatzis, E. de Bree, E. Sanidas, D. D. Tsiftsis, J. Askoxylakis, M. Daskalakis, G. Tsibinos and A. Kafatos, Ann. Nutr. Metab., 2009, 54, 275-282.

39 H. Kolarova, R. Lenobel, P. Kolar and M. Strnad, Toxicol. in Vitro, 2007, 21, 1304-1306. 